\title{
THE DEVELOPMENT OF SUPERVISORY SYSTEM FOR
}

\section{ELECTRICITY CONTROL IN SMGG, GUNTUR USING OPEN SOURCE EMBEDDED ENGINEERING}

\author{
Gajjala Ashok $^{1}$, A.V Subba Rao ${ }^{2}$, Chittazallu Durga Lavanya ${ }^{3}$, Dammala Deepika ${ }^{4}$ \\ ${ }^{1}$ Assistant Professor, Electronics \& Communications Engineering, SMGG, AP, India \\ ${ }^{2}$ Head of the Department, Electronics \& Communications Engineering, SMGG, AP, India \\ ${ }^{3}$ Student, Electronics \& Communications Engineering, SMGG, AP, India \\ ${ }^{4}$ Student, Electronics \& Communications Engineering, SMGG, AP, India
}

\begin{abstract}
The main intention of the paper is to build a prototype model, for to supervise the electricity control and monitoring for the purpose of ease of operation, power saving, man power reduction. The paper may also aimed for to help society, how to build application oriented designs for the purpose of human need to simplify the lifes using open source hardware and software tools. The worlds knows the scarcity of power. So many techniques available to monitor and control. But how the paper is new? The reason is this, the paper is developed completely using open source hardware and software which follows laws of lumped matter approaches and fundamental physics rules. The SCADA software price in multiples of thousands in Indian rupees. The authors developed SCADA software using open source tools. The SCADA software interact with the hardware in real time. The authors proposed method of approach is much simpler and economical. The authors developed prototype model to apply in St.Marrys Group of Institutions, Guntur, Ap, India. The paper is developed in following manner, 1) Problem identification in organization, 2) Practical concept development and mathematical supplementary work 3) Flow chart of working mechanism and architectural development 4) Hardware \& Software development according to Architecture.5) And finally results and discussion. The word SCADA in long form Supervisory Control and Data Acquisition. The paper combined so many fields of eng ineering and physical sciences by name Sensor technology, System On chip, Microcontrollers, Electromagnetism, software application development. The entire electrification routing in the organization is connected to SCADA Software in serial connection with centralized Personal Computer. The sensors are interfaced in server rooms which are monitoring room critical temperature. If temperature sensors feeds the data to SCADA, if the readings are out of range, the AC will ON by observer. In the same manner power control will be takes place.
\end{abstract}

Keywords: SCADA, Open source, Hardware, Software, Mathematics, Electricity, Monitoring. Etc. $* * *$

\section{INTRODUCTION}

Its hobby of authors, to stars with two most fundamental questions. Those are, what is an engineering? And what is a mathematics? The definition like to use, Engineering is to be purposeful use of science according MIT, USA and Mathematics is language, not only language but also with reasoning according to Rechard P.Feyman, the theoretical physicist, Nobel prize winner and legendary teachers, CalTech, USA.

The world has been changed a lot as compared to $20^{\text {th }}$ century because of rapid development in semiconductor devices, who follows basic physics rules. The scientist's builds fantastic electronic device based on lumped matter discipline, which can simplifies human life more simple. The author goal is also to simplify the system in view point control mechanism. 


\section{ST.MARRY'S GROUP OF INSTITUIONS ARCHITECTURAL PLAN IN 2D}

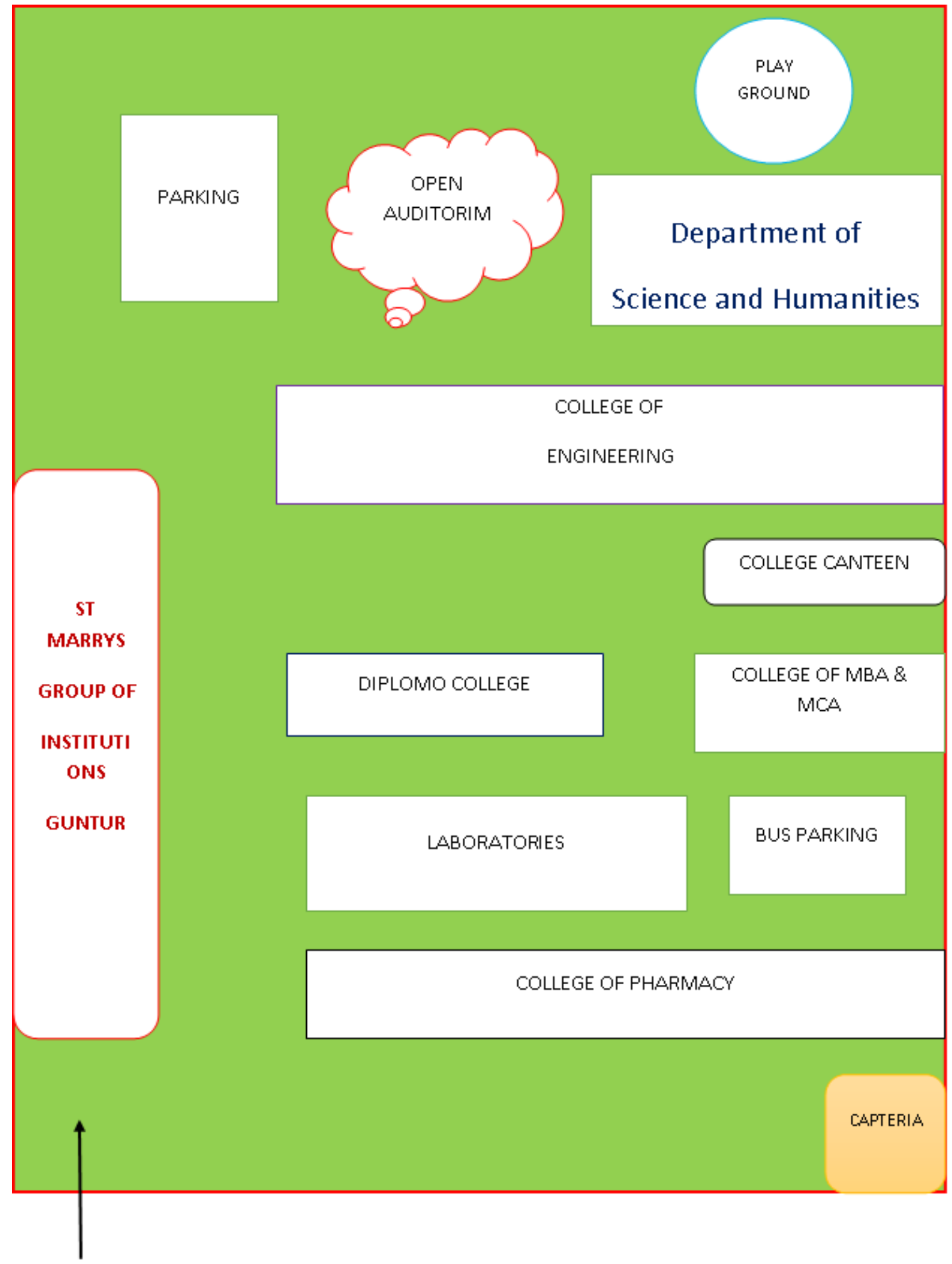




\section{RELATED WORK}

\subsection{Problem Defining}

i) In the section 2 the figure shows the building plan of college, so big college in area occupied, so monitoring of college in view point power wastage is some hard task. And lightning college is also hard stuff.

ii) The ACs are running in server rooms over a day irrespective temperatures, the thinking point is ACs not severs or purpose, those are running free. In result power wastage. iii) And finally, the students doesn't stop the fans while leaving. Sometimes there may be a chance to happen that if the power is off before classes closed in such cases students forget to turn off switches, resulting fans running over the night.

\subsection{Architecture of the Proposed Design}

The following figure shows the architectural development.

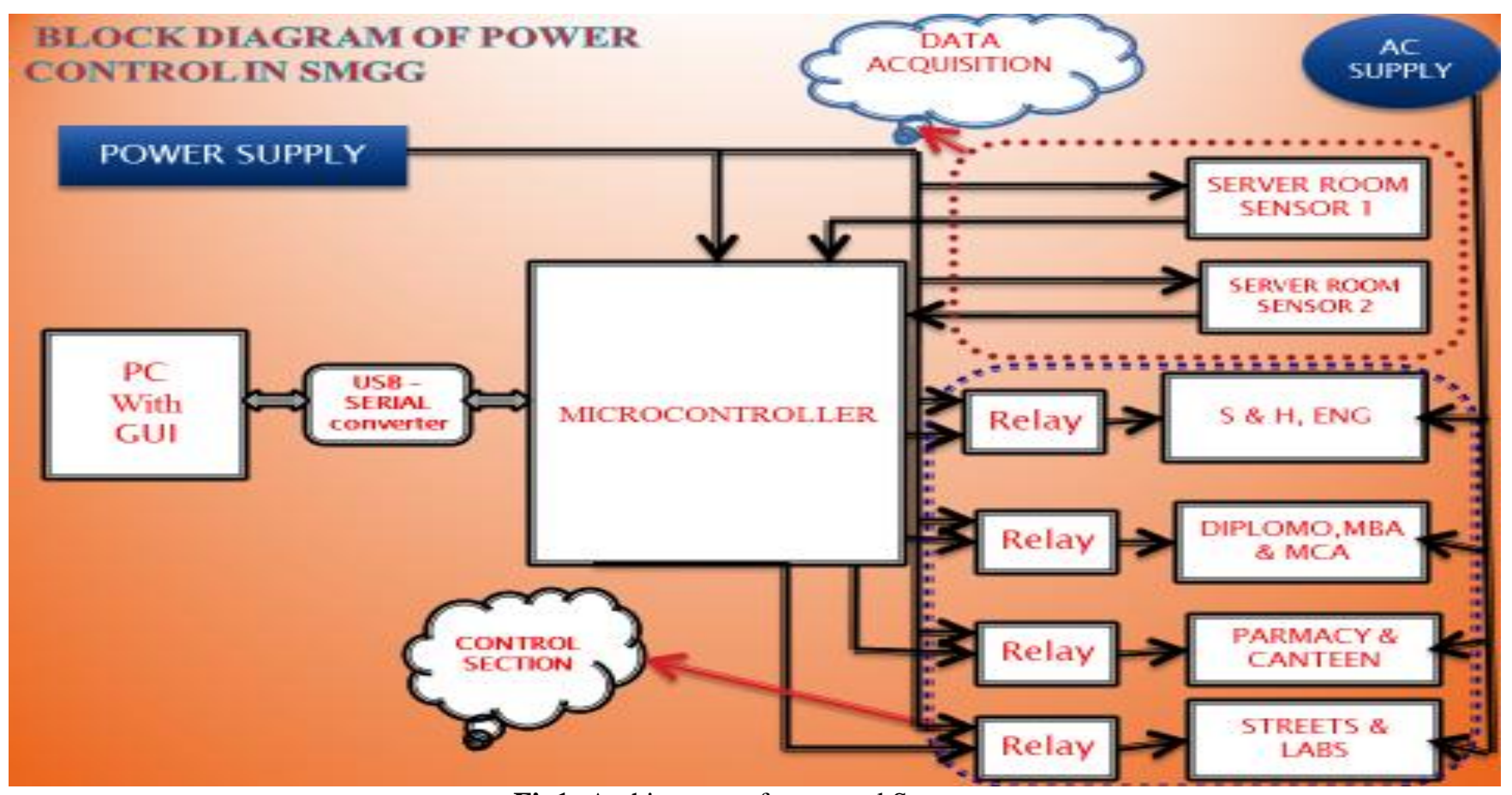

Fig1: Architecture of proposed Systems

The architecture have the following things, GUI( Graphical User Interface), who can interact with the hardware, in the other sense, that the GUI sends some symbols or codes or inputs to microcontroller to operate required operation, the microcontroller receives the signal and operates entire system. The microcontroller have SOC features. We need not look for the additional things. The Relays are the electromechanical devices. The relays responds for digital inputs and isolates the systems. The entire section is labeled as controlling section and have a look on the acquisition section, here temperature sensors are arranged in server rooms. The problem with server rooms, the room temperature should maintain at $27 \mathrm{C}$, otherwise there might be a chance to hang systems. So based on sensor data, the operator maintains room temperature at constant from centralized PC, which simplifies the job and at the same, reduces the power wastage.

\subsection{Science and Technologies Usage}

In the paper, authors used so many fields of engineering and technology integration. In this section, authors going to brief out those technogies.

\subsubsection{Temperature Sensor}

The temperature sensor used semiconductor type. The wellknown phenomena is junction temperature is dependent on the room temperature. So according junctio temperature, the current varies, and scale them to represent the temperature. The scaling of current is needed a strong predominant programming skills and complete understanding of systems is need. The typical diagram as follows.

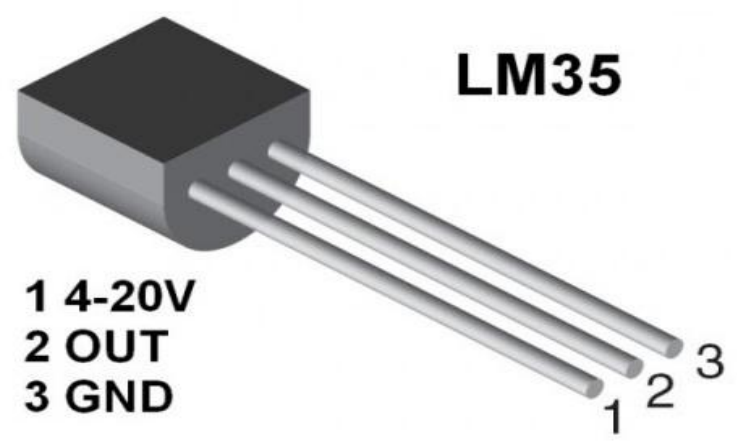

Fig 2: Outer view of temperature sensor 


\subsubsection{Relay}

The main intention of electronic relay which is used to isolated the AC systems for power line. Which means to say that, is respond to digital logics. The working priciple of elctromagnetism. The magnetic field produced by electromagnet will attract the magnetic material. Conducting material is obviously of a magnetic material. So, the machanishm of coil to produce magnetic forces of lines which attacts near by switch. If the relay receives the signal of volatage $5 \mathrm{v}$

The voltage is capable of produecing the elctromagnetic forces of lines which can attracts near by switch. Then after closing the switch, power up the particualr section. The relays will be diagramatically shown below .

The figures shows clearlly about the machanishm of exact behavior of what we want . Ofcource we didn't build the relay by our own, as it is commertially available in market.

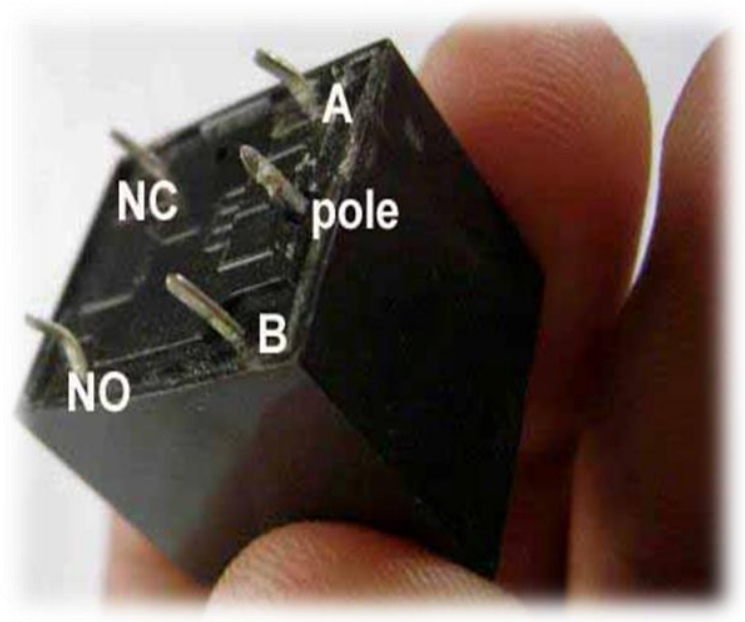

Fig 3: Commertially available relays in market

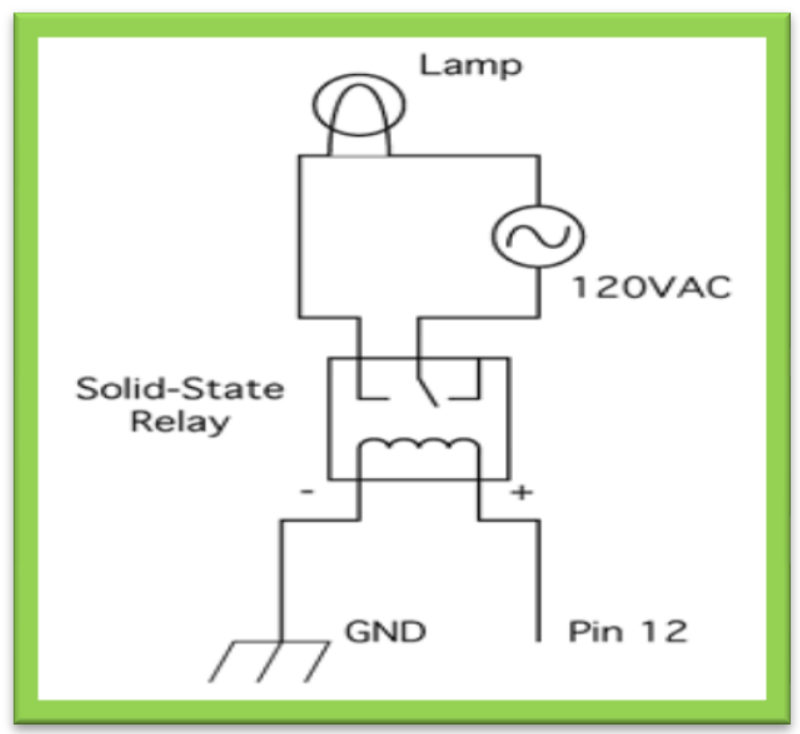

Fig 4: Typical Internal Arrangement of Relay

\subsection{Open Source Hardware}

The open source material available in present days, in example Arduino compatable harware . By using arduino we can built an interesting engineering projects to change the shape of the real world which simplyfies the human being's life to be better. The typical arrangement of open source hardware is shown in the following figure. The programming can be employed in Arduino IDE( integrated development environment ). The IDE supports java scripting language. And most important thing is, we can implement very typical things, would I mean to say that we can handle complex tasks in simple manner.

The authors, would like to notice few things, those are, arduino compatable hardware have in-built ISP( In System Programming )., The facilities needs to communicate with the real world have in built of chip,this is right time to lable the chip name AtMega AVR Family.

And most important thing is that, the bootloader and Read While Right Operation, which helps us to run systems in paraller. The main goal paralleism is reduce computational time to do task. It has in-built ADCs of sucessive approximation type.

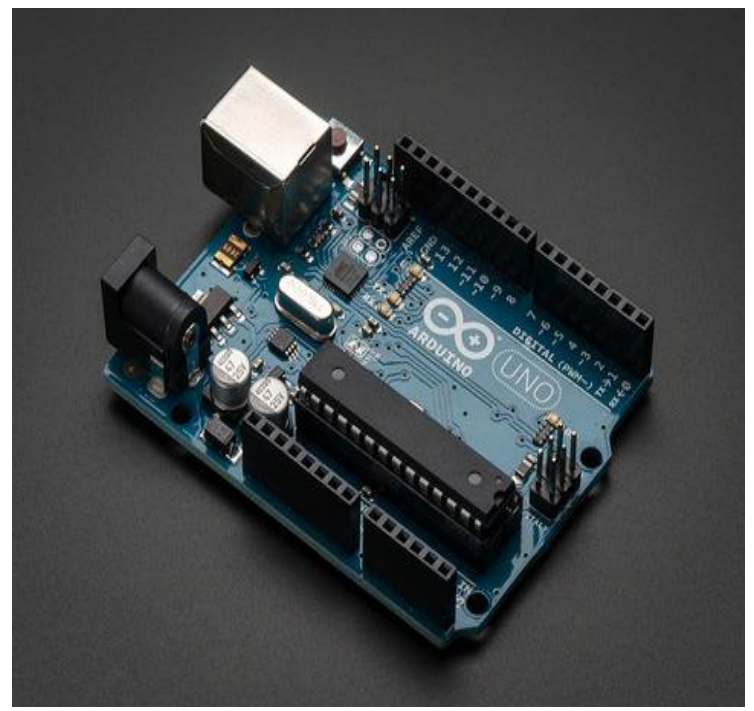

Fig 5: Open source Arduino Hardware 


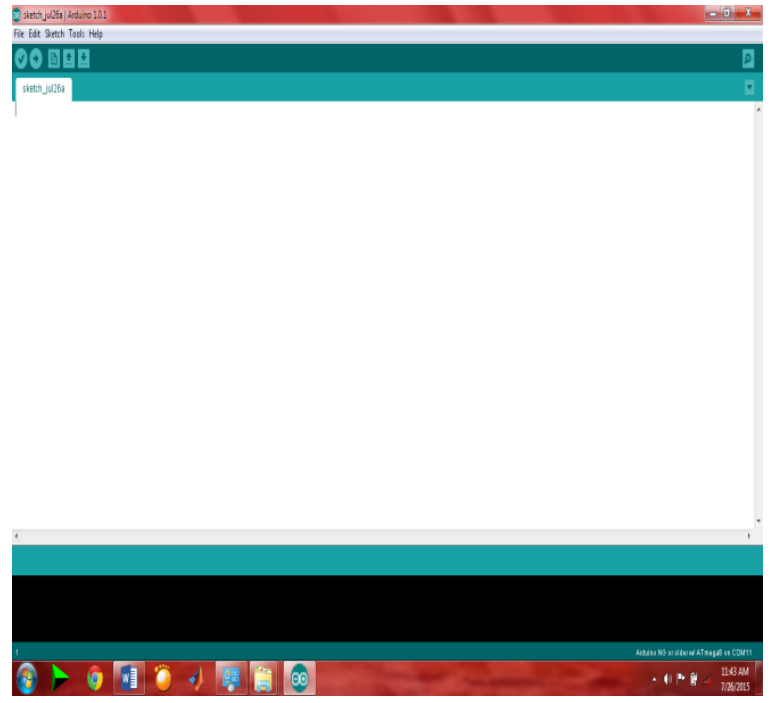

Fig 6: Arduino program development IDE

\section{WORKING MECHANISHM}

i) The main intention of the project is to build a prototype model, for to supervise the electricity control and monitoring for the purpose of ease of operation, power saving, man power reduction. ii) The project may also aimed for to help society, how to build application oriented design for the purpose of human needs to simplify the life using open source hardware and software tools.

iii) The architecture has have the following thing, GUI( Graphical User Interface), who can interact with the hardware, in the other sense, that the GUI sends some symbols or codes or inputs to microcontroller to operate required operation, the microcontroller receives the signal and operates entire system.

iv) The microcontroller have SOC features. We need not look for the additional things. Like Relays are the electromechanical devices.

v) The relays responds for digital inputs and isolates the systems. The entire section is labeled as controlling section and have a look on the acquisition section, here temperature sensors are arranged in server rooms.

vi) The problem with server rooms, the room temperature should maintain at $27 \mathrm{C}$. otherwise there might be chance to hang systems. So based on sensor data, the operator maintain room temperature at constant from centralized PC, which simplifies the job and at the same, reduces the power wastage

\subsection{Digital Logical Operations}

Table1: Digital logics for controlling

\begin{tabular}{|l|l|l|l|l|l|l|}
\hline \multirow{2}{*}{ S.NO } & \multicolumn{2}{|l|}{ GUI Status } & \multicolumn{2}{l|}{$\begin{array}{l}\text { Microcontroller } \\
\text { Status }\end{array}$} & $\begin{array}{l}\text { Relay Section } \\
\text { Status }\end{array}$ & SMGG Colleges \\
\cline { 2 - 7 } & & $\begin{array}{l}\text { Gui Status } \\
\text { BITS }\end{array}$ & $\begin{array}{l}\text { Input } \\
\text { Port }\end{array}$ & $\begin{array}{l}\text { Output } \\
\text { Port }\end{array}$ & Close / Open & Opreration Status \\
\hline 1 & Power Section 1 & 1 & 1 & 1 & Closed & Power on \\
\hline 2 & Power Section2 & 0 & 0 & 0 & Open & Power Off \\
\hline 3 & Power Section3 & 1 & 1 & 1 & Closed & Power on \\
\hline 4 & Power Section4 & 1 & 1 & 1 & Closed & Power on \\
\hline
\end{tabular}

The entire electrification routing in the organization is connected to SCADA Software in serial connection with centralized Personal Computer. The sensors are interfaced in server rooms which are monitoring room critical temperature. If temperature sensors feeds the data to SCADA, if the readings are out range, the $\mathrm{AC}$ will be $\mathrm{ON}$ by observer. In the same manner power control will be takes place.

\section{RESULTS \& DISCUSSIONS}

There are few snapshot of results during the execution of prototype model.

i) The figure7 shows the satellite image of college top view taken with searching website www.maps.google.in

ii) The developed prototype model is shown in figure 8 .

iii) The developed SCADA windows is shown in figure 9. This is the main primitive thing, who can communicate with the outside world. iv) The figure 10 shows the temperature reading, based on reading then supervisor takes a decision whether to $\mathrm{ON}$ the AC or not?.

v) The figures 11, 12 shows controlling of particular college power supply. Which is clearly shows in following snapshots 


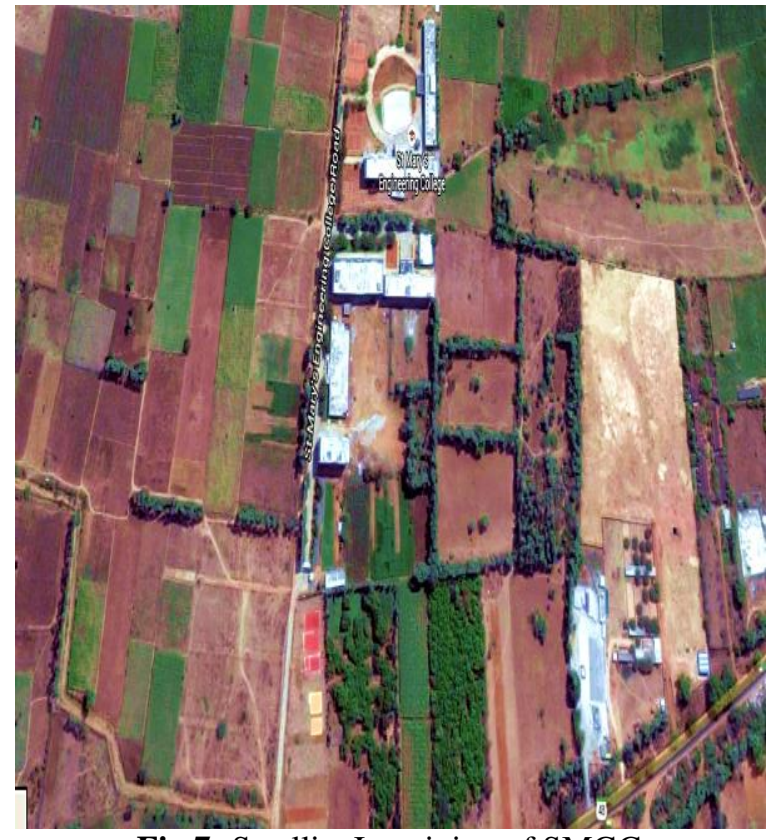

Fig 7: Satellite Imagining of SMGG

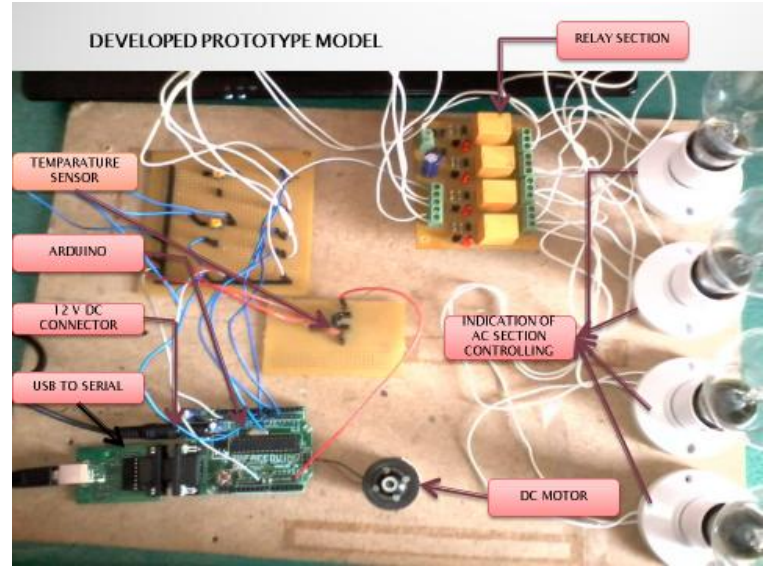

Fig 8: Prototype Model

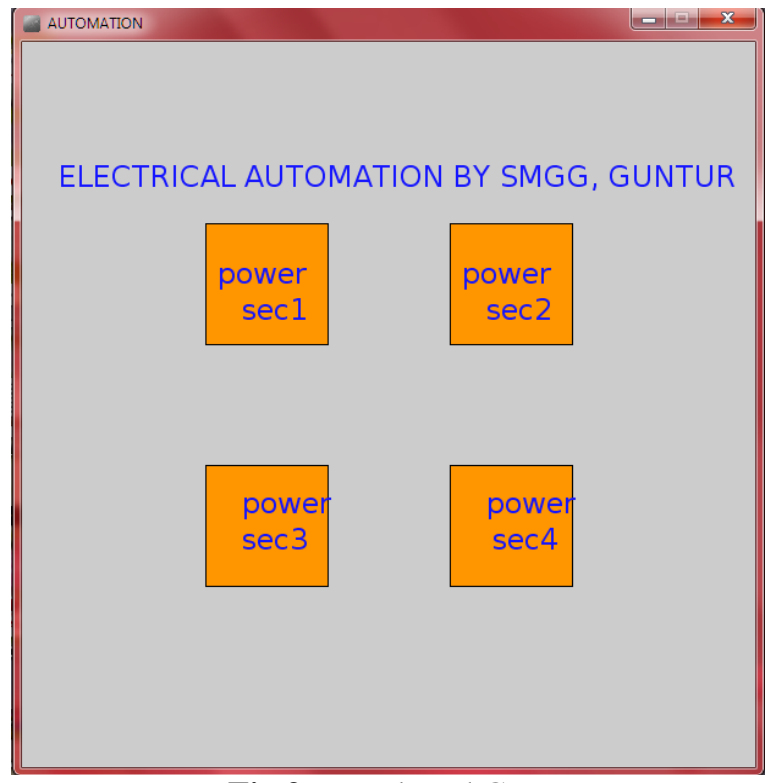

Fig 9: Developed GUI

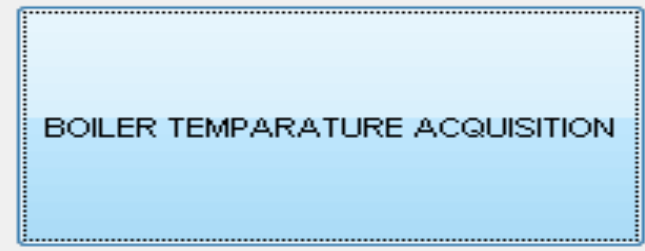

26

Fig 10: Temperature acquisition

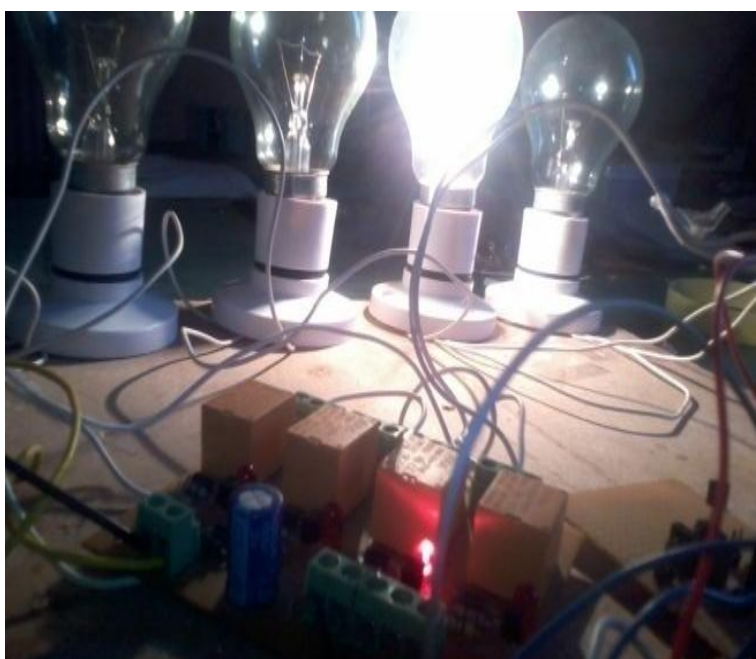

Fig 11: Powering the Section

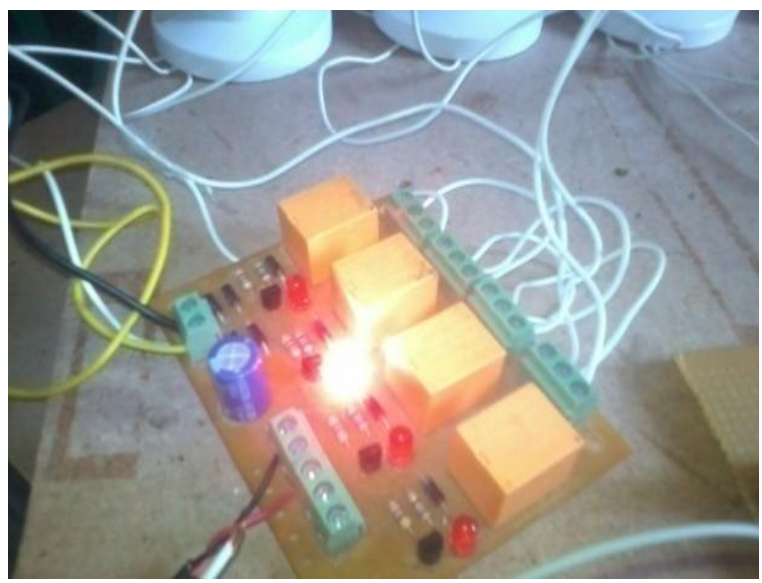

Fig 12: Relay closing regarding particular section

\section{CONCLUSION \& APPLICATIONS}

The authors are concluding few major things

1) The project definitely helps SMGG to reduce electricity billing amount about 50,000/-.

2) The project reduces man power.

3) It provides ease of operation.

4) There is need for skilled engineer to monitor, the interactive GUI helps what to do? The authors prospective is one who knows English they can operate the entire power section. 
5) Finally, the project may also applicable to smart cities, high risky place etc.

Notice that the project is developed with open source tools. In Resulting it is economical.

\section{ACKNOWLEDGEMENTS}

The authors would like to express sincere thanks to governing body of SMGG, Guntur specially KVK RAO Garu, for providing quality education India wide. SMGG searching for good teaching \& Research methods to improve student skills to fit in global world.

The authors would like to express my sincere gratitude to former SMGG Director R SRINIVASA RAO Garu, Principal Dr. G MURALI Garu, Vice Pricipal Y RAGAVA Garu, and RAVIBABU Garu, AV SUBBARAO Garu HOD of ECE, for his valuable support and encouragement during the work.

Finally our colleagues by names SK Imam, Tulasi Jaami, M.Sai Krishna, Sk.Masthanbee, Rajesh, Mahesh, D.Subharao, R Rajasekhar, M.Chiranjeevi, Srinu naik Bhavya Sree Kalyani,Vinode, Prasana, bhanumathi, Ramakrishna, Mounica, for their encouragement and support. In last our beloved students who is receiving our lectures, because of them we are looking the subject in different prospective.

Ch.D Lavanya \& D. Deepika :

Our passion towards learning bought us here with this project with the help of my lecturer. We wanted to dedicate this work to my college as my college always stays beside us by supporting and making us to learn. Our confidence adds up with the teamwork which leads to success.

\section{REFERENCES}

[1] Michael Barr.Embedded Systems Glossaryv Neutrino Technical Library. Retrieved2007-04-21.

[2] Heath, Steve Embedded systems design. EDN series for design engineers Newnes. An embedded system is a microprocessor based system that is built to control a function or a range of functions.

[3] Michael Barr; Anthony J. Massa Introduction Programming embedded systems: with $C$ and $G N U$ development tools. O'Reilly.

[4] Caliph: Intelligence for Embedded Systems Springer, 2014, 283pp, ISBN 978-3-319-05278-6.

[5] S. Mittal, A survey of techniques for improving energy efficiency in embedded computing systems", IJCAET, 6(4), 440-459, 2014.

[6] Giovino, Bill.Micro controller.com Embedded Systems supersite".

[7] Electronic Voting Machine Information Sheet Accupoll AVS 1000

[8] Embedded Systems Dell OEM Solutions | Dell. Content.dell.com (2011-01-04). Retrieved on 201302-06.
[9] Embedded.com - Under the Hood: Robot Guitar embeds auto tuning. By David Carey, Tech Online EE Times Embedded Systems Design Embedded.com

[10] Tektronix Shakes Up Prototyping, Embedded Instrumentation Boosts Boards to Emulator Status. Electronic Engineering Journal. 2012-10-30. Retrieved 2012-10-30.

[11] Heiser, Gernot (December 2007). Your System is secure?

[12] Working across Multiple Embedded Platform clarinox.

\section{BIOGRAPHIES}

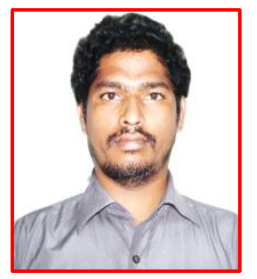

G Ashok, He is currently working as Asst, Processor Dept. of ECE, SMGG, and Guntur. He teaches at SMGG, signal \& systems, Probability \& Stochastic Processing, Digital Signal Processing, Circuits \& Systems, and Digital Image Processing. He has 3 and half years of Teaching \& Research Experience. He published few International Journal's. He had B.Tech \& M.Tech from JNTUA. Area of Research, Electromagnetism, Artificial Neural Networks, Superconductivity, Intellectual systems design. Follow him on:

http:Iwww.howtoadapttonewtechonology.blogspot.com

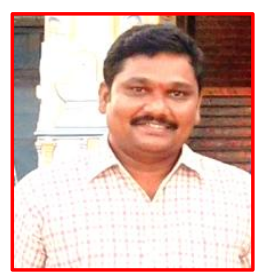

AV Subba Rao, $\mathrm{He}$ is currently working as HOD, Dept. of ECE, SMGG, and Guntur. He teaches at SMGG, signal \& systems, Probability \& Stochastic Processing, Digital Signal Processing, Circuits \& Systems, and Digital Image Processing finally all subjects in in ECE discipline. He has 12 years of Teaching Experience. He published few International Journal's. He had B.Tech \& M.Tech from JNTUH. Area of Research, Digital Image Processing, VLSI Design, Control Systems.

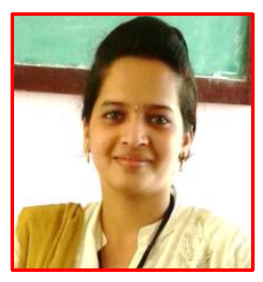

C.D Lavanya, She is pursuing fourth year B.Tech in stream of ECE. She has good and fantastic enthusiastic nature of learning new technologies. She spends a lot of time to learn new things, and thinks in logical manner. She asks a lot questions during lecture. This is the fundamental quality of student. Her research interests are Real Time Embedded Systems and Complex task handling process.

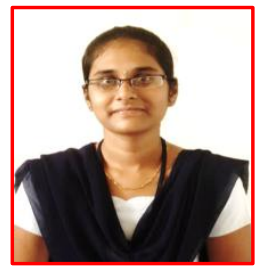

D.Deepika, She pursuing fourth year B.Tech in stream of ECE. She has good and fantastic enthusiastic nature of learning new technologies. She spends a lot time to learn new thing, and thinks in logical manner. She ask a lot questions during lecture. This is the fundamental quality of student. Her research interests are VLSI Design and Hardware \& Software Co-Design. 